\title{
Technological Features of Selected Kivuguto Strains during Milk Fermentation
}

\author{
Eugene Karenzi ${ }^{1, *}$, Marie-Laure Fauconnier ${ }^{2}$, Jacqueline Destain ${ }^{1}$, Pascal Laurent ${ }^{3}$, Philippe Thonart ${ }^{4}$ \\ ${ }^{1}$ Unit of Bioindustries, Gembloux Agro-Bio Tech, University of Liège, Belgium \\ ${ }^{2}$ Unit of General \& Organic Chemistry, Gembloux Agro-Bio Tech, University of Liège, Belgium \\ ${ }^{3}$ Free University of Brussels, Faculty of Medicine, Belgium \\ ${ }^{4}$ THT s.a., Parc Scientifique CREALYS, 17 Rue Camille Hubert, Belgium
}

Copyright (C) 2015 Horizon Research Publishing All rights reserved.

\begin{abstract}
Kivuguto milk is a traditional fermented milk of Rwanda. A previous study allowed for the selection of three bacteria involved in the fermentation process. The aim of the present work is the technological characterization of kivuguto strains for its production in the dairy industry. Acidification, proteolysis, the flavor compound profile, rheology and sensory analyses of fermented milks were assessed as important indicators of the starter culture formulation. Acidification showed that kivuguto milk ferments in 14 hours at $19^{\circ} \mathrm{C}$ with a titratable acidity of $73^{\circ} \mathrm{D}$. The samples of CWBI-B1466 Lactococcus lactis and CWBI-B1470 Leuconostoc pseudomesenteroides had fermentation times of $14 \mathrm{~h}$ and $20 \mathrm{~h}$, respectively. All samples were viscoelastic fluids, and the most important flavor compounds found were two alcohols, one ester and two furan derivative compounds. Proteolysis revealed low values ranging to $3.04-5.45 \mathrm{mg} . \mathrm{L}^{-1}$, which is very interesting in terms of taste acceptability. The three strains showed positive technological properties for kivuguto starter culture development and the data are fully in agreement with the preliminary results of the technological analyses. The findings revealed similarities between the formulated kivuguto and the traditional kivuguto as recognized by a tasting panel in a discrimination test. Ultimately, this study allowed for the formulation of kivuguto milk using three bacteria, prior to studying the stability of these properties during storage under refrigeration, which is the last stage before industrial production of kivuguto milk can begin.
\end{abstract}

Keywords Technological Features, Kivuguto, Milk Fermentation, Acidification, Rheology, Proteolysis, Aroma Compounds, Sensory Analysis

\section{Introduction}


because of its influence on consumer acceptance [10]. According to Thomas [11], consumer acceptance and the preference for milk as a beverage is influenced by its flavor more than any other attribute. The typical flavor of fermented milks is derived from lactic acid and many carbonyl compounds produced by starter cultures. Lactic acid is responsible for the sharp, refreshing taste of these products [12]. Another source of flavor compounds is the thermal degradation of lipids, lactose and proteins during the heat treatment of milk before fermented milk manufacture e.g. aldehydes, ketones, alcohols, lactones, and sulfur compounds [13].

Kivuguto milk is manufactured by spontaneous fermentation or by backslopping in Rwanda. The milk is more appreciated by local consumers than modern fermented milks produced on the Rwandan market. To date, no investigations have been conducted on the manufacturing techniques, neither on the physicochemical and organoleptic characteristics, nor on any other technological parameter. In a previous study [14], three strains were selected for kivuguto starter formulation: CWBI-B1466 Lactococcus lactis registered under Genbank accession number JF313446, CWBI-B1465 Leuconostoc mesenteroides subsp. mesenteroides, accession number JF313445 and CWBI-B1470 Leuconostoc pseudomesenteroides, accession number JF313454.

The present paper deals with the main technological properties used to characterize kivuguto milk using these strains. Additionally, a sensory analysis was performed by an untrained panel as a validation test of similarities between the kivuguto produced by the selected starter bacteria and the traditional one. Ultimately, the purpose of this work is the industrial production of this milk. To the best of our knowledge, no study has been conducted before with an investigation into the technological properties of this traditional milk. Moreover, our approach uses the best methodology for fermented milk formulation, as it analyzes four main technological properties after microbial selection.

\section{Materials and Methods}

\subsection{Bacterial Strains and Milk Fermentation}

The selected microorganisms for fermenting kivuguto were preserved at $-80^{\circ} \mathrm{C}$ at the CWBI Collection (Walloon Center of Industrial Biology) and registered in the Genbank database. The three strains were CWBI-B1466 Lactococcus lactis, registered under Genbank accession number JF313446, CWBI-B1465 Leuconostoc mesenteroides subsp. mesenteroides, accession number JF313445 and CWBIB1470 Leuconostoc pseudomesenteroides, accession number JF313454. Prior to this experiment, assays were performed with many fractions of each strain to find a fermented milk similar to kivuguto; one formulation was retained for further analyses. Attention was paid to the enumeration data obtained during the selection, as a reference proportion. The incubation temperature was fixed to $19^{\circ} \mathrm{C}$. The flasks were then incubated until a $\mathrm{pH}$ of $\approx 4.5$ was reached and thereafter stored at $4{ }^{\circ} \mathrm{C}$ before analyses. The preparation of samples was made using four milks:

$1^{\circ} \mathrm{M} 1$ : whole milk fermented with the mixed kivuguto starters composed of three selected strains CWBI-B1466 Lactococcus lactis, CWBI-B1465 Leuconostoc mesenteroides and CWBI-B1470 Leuconostoc pseudomesenteroides at a ratio of $40 \%, 35 \%$ and $25 \%$, respectively. The pre-culture was inoculated at $10^{6}$ cells.g $^{-1}$ as the initial concentration. This inoculum was used to culture at $4 \%(\mathrm{vol} / \mathrm{vol})$ in $2 \mathrm{~L}$ of UHT milk in a $5 \mathrm{~L}$ flask.

$2^{\circ} \mathrm{M} 2$ : whole milk fermented with strain CWBI-B1466 Lactococcus lactis at $10^{6}$ cells.g $^{-1}$ as the initial concentration for pre-culture and used as an inoculum at $4 \%$ (vol/vol) in $2 \mathrm{~L}$ of UHT milk (ultra high temperature) in a 5 L flask.

$3^{\circ}$ M3: whole milk fermented with strain CWBI-B1470 Leuconostoc pseudomesenteroides at $10^{6}$ cells. $\mathrm{g}^{-1}$ as the initial concentration for pre-culture and used as an inoculum at $4 \%(\mathrm{vol} / \mathrm{vol})$ in $2 \mathrm{~L}$ of UHT milk in a $5 \mathrm{~L}$ flask. $4^{\circ}$ M4: UHT milk used for fermentation. Tests were carried out without inoculation.

\subsection{Acidification and Enumeration}

Milk cultures of each sample were inoculated at ambient temperature and the $\mathrm{pH}$ (WTW $\mathrm{pH} 351 \mathrm{i} \mathrm{pH}$ meter, Weilheim, Germany) and titratable acidity $\left({ }^{\circ} \mathrm{D}\right)$ were measured after incubation time by titrating a $10 \mathrm{~mL}$ sample with $\mathrm{NaOH}(1 / 9 \mathrm{~N})$ using phenolphthalein as the indicator. The titratable acidity was measured in Dornic degrees $\left({ }^{\circ} \mathrm{D}\right)$; under such conditions, $1^{\circ} \mathrm{D}$ is equivalent to $0.1 \mathrm{~mL}$ of $\mathrm{NaOH}$, i.e. $0.1 \mathrm{~g}$ lactic acid per $\mathrm{kg}$ of milk. For the biomass count, suitable dilutions were made and plated on MRS agar medium. Results were the average of three independent measurements.

\subsection{Rheological Properties}

The rheology characterization of the kivuguto milk was performed by a description of its viscoelastic behavior using an oscillatory model rheometer. The rheological parameters storage modulus $\left(\mathrm{G}^{\prime}\right)$ and loss modulus ( $\left.\mathrm{G}^{\prime \prime}\right)$ were followed as a function of time at $10^{\circ} \mathrm{C}$ using a high resolution Bohlin CVO 120 rotational rheometer (Malvern Instruments, Worcestershire, UK). The measuring geometry employed was a rotating upper cone and a fixed lower plate $\left(\alpha=4^{\circ}, \varnothing=40 \mathrm{~mm}\right)$. The oscillation frequency was $1.0 \mathrm{~Hz}$ and the shear stress was $1 \mathrm{~Pa}$, which was found to be within the linear viscoelastic region of fermented milk samples according to Stern et al. [15]. Three replicates were assessed.

\subsection{Proteolysis}

The peptides/free amino acids (FAAs) accumulated in 
milk after the incubation time as a consequence of the proteolytic activity of the tested strains were determined using the o-phthaldialdehyde (OPA) method [16]. This method is based on the reaction of OPA and 2mercaptoethanol with the $\alpha$-amino groups released during the hydrolysis of milk proteins. They form a complex which absorbs strongly at $340 \mathrm{~nm}$. The OPA solution is obtained by combining the following reagents and completing a volume of $50 \mathrm{~mL}$ with water: $25 \mathrm{ml}$ of $100 \mathrm{mM}$ sodium tetraborate (Sigma Aldrich, Diegem, Belgium), $2.5 \mathrm{~mL}$ of 20\% SDS (Merck, Darmstadt, Germany), 40 mg OPA (Sigma Aldrich, Diegem, Belgium) dissolved in $1 \mathrm{~mL}$ of methanol and $100 \mu \mathrm{L}$ of 2-mercaptoethanol (Sigma Aldrich, Diegem, Belgium). This reagent should be prepared on the same day as the assay. To measure the proteolytic activity, with milk protein as the substrate, a $150 \mu \mathrm{L}$ aliquot (of a 1:25 dilution of milk in 1\% SDS) was added to $3.0 \mathrm{ml}$ of the OPA reagent. The solution was stirred by inversion and incubated for 2 minutes at room temperature, and the absorbance is measured at $340 \mathrm{~nm}$ using a Genesys $10 \mathrm{~S}$ UV-VIS spectrophotometer (Thermo Fisher Scientific, Madison, WI, USA). The results from triplicates were calculated from a standard curve obtained from the dilution of leucine in distilled water and expressed in leucine equivalents (mg.L ${ }^{-1}$ ) (Sigma Aldrich, Diegem, Belgium) in milk.

\subsection{Aroma Compounds}

Headspace sample preparation. Headspace (HS) samples were prepared manually. A $10 \mathrm{~g}$ milk sample was introduced in a $20-\mathrm{mL}$ HS vial (Filter Service, Eupen, Belgium), hermetically sealed with a polytetrafluoroethylene-coated rubber septum and an aluminum cap (Filter Service, Eupen, Belgium). The sample was kept at $4^{\circ} \mathrm{C}$ after fermentation for a short time before analysis. Otherwise, samples were kept at $-20^{\circ} \mathrm{C}$ and put at $4^{\circ} \mathrm{C}$ the day before analysis. Samples were equilibrated for $65 \mathrm{~min}$ at $70^{\circ} \mathrm{C}$ prior to analysis and the volatile compounds trapped in the headspace region of the vial $(2000 \mu \mathrm{L})$ were collected with a microsyringe (Filter Service, Eupen, Belgium) and analyzed by gas chromatography (GC) using direct gas injection.

Gas chromatography. Milk sample volatiles $(2000 \mu \mathrm{L})$ were injected into an Agilent Technologies 7890A GC System (Agilent Technologies, Santa Clara, CA, USA) equipped with a flame ionization detector (FID) and a $30 \mathrm{~m}$ x $250 \mu \mathrm{m}$ x $0.25 \mu \mathrm{m}$ VF-WAX polar column (Agilent Technologies) was used for the study. Helium was used as the carrier gas, at a flow rate of $1.5 \mathrm{ml} \cdot \mathrm{min}^{-1}$; splitless mode was used. The following temperature program was used: $50^{\circ} \mathrm{C}$ for $6 \mathrm{~min}$, increased to $180^{\circ} \mathrm{C}$ for $5 \mathrm{~min}$ at a rate of $8^{\circ} \mathrm{C} \cdot \mathrm{min}^{-1}$ and held $10 \mathrm{~min}$ at $15^{\circ} \mathrm{C} \cdot \mathrm{min}^{-1}$ from 180 to $250^{\circ} \mathrm{C}$. The injector and detector temperatures were $220^{\circ} \mathrm{C}$ and $250^{\circ} \mathrm{C}$, respectively.

Mass spectrometry analysis. The volatile compounds were identified by mass spectrometry (MS) using an
Agilent Technologies 5875C with Triple-Axis Detector coupled to 6890 GC System (Agilent Technologies). MS was carried out in electron ionization (EI) mode, with an ionization potential of $70 \mathrm{eV}$ and ionization current of $2 \mathrm{~A}$. The ion source temperature was $200^{\circ} \mathrm{C}$, the resolution was 1000 and the mass range was 30 to $450 \mathrm{~m} / \mathrm{z}$.

Chemical identification. Compounds were identified by comparing recorded mass spectra with the Wiley 275L mass spectra library (Scientific Instrument Service, Ringoes, NJ, USA), the NIST MS Library (NIST, Gaithersburg, MD, USA), the PAL 600K mass spectral library (Palisade Corporation, Ithaca, NY, USA) and those in the literature, as well as a comparison of their retention times with authentic standards of a saturated $n$-alkanes standard solution $\left(\mathrm{C}_{7}-\mathrm{C}_{30}\right.$ alkanes) (Sigma Aldrich, Diegem, Belgium) as external references under the same chromatographic conditions, allowing for the calculation of the Kovats index [17] of the separated volatile compounds [18].

Standard solutions and quantification. Aqueous solutions of acetic acid, pentan-1-ol, and methyl benzoate as external standards were prepared from high purity chemicals ( $>99 \%$ ) purchased from Sigma-Aldrich (Diegem, Belgium). $40 \mu \mathrm{L}$ of each standard was accurately weighed and diluted in $100 \mathrm{~mL}$ in double distilled water and thereafter mixed at a ratio of $1: 1$. The prepared solution was hermetically sealed in $20 \mathrm{~mL}$ headspace vials at $-20^{\circ} \mathrm{C}$ until they were used. Quantification of compounds was calculated by the external standard technique. The mean results of three assays were used to calculate the response factors corresponding to mean peak area for each standard compound, and the amount of each compound in the sample was calculated according to the known amount standard and its peak area. Moreover, the response factors of pentan-1-ol and methyl benzoate were used to calculate the concentrations of 3-methylbutan-1-ol and furanmethan-2-ol and 1,7,7-trimethylbicyclo [2.2.1] hept-2yl acetate and furan-2(5H)-one, respectively.

\subsection{Sensory Analysis}

A modified triangle test allowed eight panelists who were untrained but familiar with kivuguto milk to differentiate between samples and to identify the sample most similar to kivuguto according to de Lacharlerie et al. [19] in a discriminative test. The test was sought to determine between two products, A and B, which were similar to kivuguto, one of the two being kivuguto. Samples were presented in three-digit coded cups with two samples per set given to each subject. The principle is that subjects receive three samples. Two are the same product (A or B), while the third is different. Therefore, there are two options for the three samples: AAB or ABB. The randomized presentation order uses the six possible combinations of the triplet on each plate: AAB, ABA, BAA, BAB, BBA, ABB. Two sets were consecutively evaluated by the panelists and the first set was kivuguto (M1) versus the reference milk 
sold on the Rwandan market, whereas the second set was kivuguto (M1) versus yogurt, also sold on the Rwandan market. The UHT milk used to ferment the milk also came from Rwanda. Results were calculated using a table of critical values for the triangle test for differences, with the table built on a binomial distribution with EXCEL IV for the estimation of statistical significance in the sensory evaluation.

\section{Results \& Discussion}

\subsection{Cultures and Fermentation}

Fermentations assays were performed with single or mixed kivuguto starters to ferment raw sterile milk. Both the mixed or single cultures started with an initial inoculation of $10^{6}$ freeze-dried cells in a pre-culture made in a $250 \mathrm{~mL}$ flask. The best mixture was composed of $40 \%$ Lactococcus lactis, 35\% Leuconostoc mesenteroides subsp. mesenteroides and 25\% Leuconostoc pseudomesenteroides. Single and/or mixed fermentations were carried out in $2 \mathrm{~L}$ $(4 \% \mathrm{vol} / \mathrm{vol})$ of UHT milk. Acidification data are presented in Table 1.

The fermentation time in hours ended at the time when the acidification reached $\mathrm{pH} \approx 4.55$. The data show that the single cultures ended the fermentation at $14 \mathrm{~h}$ and $20 \mathrm{~h}$ for Lactococcus and Leuconostoc, respectively. For the mixed fermentation (kivuguto), the fermentation time was $14 \mathrm{~h}$. The maximum velocity $\mathrm{V}_{\mathrm{m}}$, i.e. the lactic acid produced per liter per hour after milk inoculation, was equal for kivuguto and the best acidifier (Lactococcus), i.e. 0.26 and 0.25 g.L ${ }^{-}$ ${ }^{1} \cdot \mathrm{h}^{-1}$ respectively. This data is an indication of a positive interaction of Leuconostoc cells in milk with Lactococcus, as the percentage of the inoculum of Leuconostoc cells is $60 \%$ in kivuguto, whereas in the single fermented milk of Lactococcus the inoculum was $100 \%$. This means that the acidifying activity of $40 \%$ Lactococcus in kivuguto is equally balanced by $60 \%$ Leuconostocs. The $\mathrm{V}_{\mathrm{m}}$ of Leuconostoc pseudomesenteroides was $0.17 \mathrm{~g} . \mathrm{L}^{-1} \cdot \mathrm{h}^{-1}$. Note that the lag phase was $4 \mathrm{~h}$ for kivuguto and Lactococcus milks, and $7 \mathrm{~h}$ for Leuconostoc pseudomesenteroides milk, meaning that Lactococcus is more active than Leuconostoc after inoculation. Juillard et al. [20] found the same result when culturing milk with mixed thermophile lactic acid bacteria. In addition, the lactic acid produced in mixed cultures was greater than that in single cultures $\left(7.3 \mathrm{~g} . \mathrm{L}^{-1}\right.$ for kivuguto, 7.2 g.L $\mathrm{L}^{-1}$ for Lactococcus milk and $7.0 \mathrm{~g}$.. ${ }^{-1}$ for Leuconostoc milk). Oliveira et al. [21] found two-fold a many lactic acid bacteria produced by mixed cultures compared to single culture milks using Bifidobacteria cells. The cell count at the end of fermentation ranged from 3.3 $10^{9}$ to $4.210^{9}$ cfu. $\mathrm{mL}^{-1}$ for the three samples.

\subsection{Rheological Analyses}

Small deformation oscillatory testing was applied for the evaluation of kivuguto milk rheology. The $\mathrm{G}^{\prime}$ and $\mathrm{G}^{\prime \prime}$ data evolution over time are presented in Figures 1, 2 and 3.

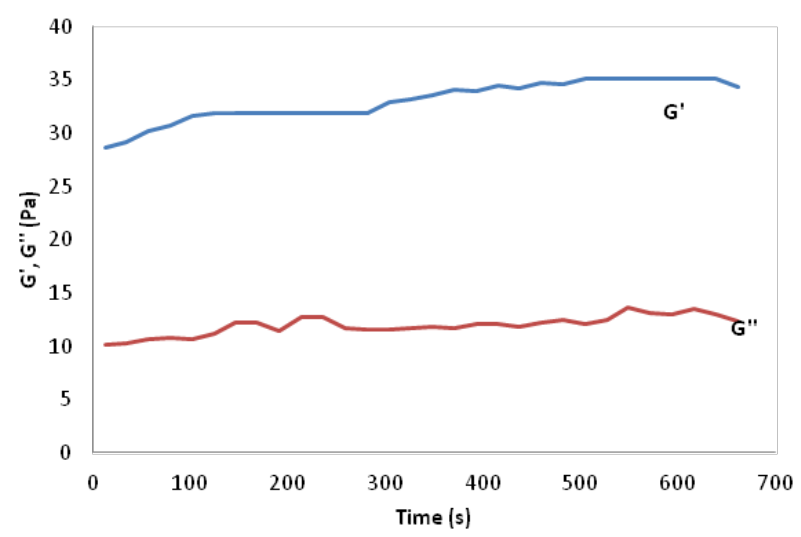

Leuconostoc pseudomesenteroides in fermented milk at $\mathrm{pH} 4.5$

Figure 1. Elastic moduli and loss moduli evolution (time in secondes) of the strain CWBI-B1470

The results show an increase up to $10 \mathrm{~min}$ for both $\mathrm{G}^{\prime}$ and $G^{\prime \prime}$. First, the experiment was applied with single strains of kivuguto milk, i.e. fermentative strains of CWBI-B1466 Lactococcus lactis and CWBI-B1470 Leuconostoc pseudomesenteroides. The results show in two cases that $\mathrm{G}^{\prime}>\mathrm{G}^{\prime \prime}$ and never $\mathrm{G}^{\prime \prime}>\mathrm{G}^{\prime}$, meaning that no liquid form was described by the two milks. Instead, the two milks showed an increase up to $10 \mathrm{~min}$ of $\mathrm{G}^{\prime}$ and $\mathrm{G}^{\prime \prime}$, with a higher value of $\mathrm{G}^{\prime}$ in the milk fermented with CWBI-B1470 Leuconostoc pseudomesenteroides than that with CWBI-B1466 Lactococcus lactis.

Table 1. Acidification data of milk fermented by selected kivuguto strains at $19^{\circ} \mathrm{C}$

\begin{tabular}{|c|c|c|c|c|c|}
\hline Culture & $\begin{array}{c}\mathrm{T}_{\mathrm{L}} \\
(\mathrm{h})\end{array}$ & $\begin{array}{c}\mathrm{T}_{\mathrm{f}} \\
(\mathrm{h})\end{array}$ & $\begin{array}{c}\mathrm{V}_{\mathrm{m}} \\
\left(\mathrm{g} \cdot \mathrm{L}^{-1} \cdot \mathrm{h}^{-1}\right)\end{array}$ & $\mathrm{pH}_{\mathrm{f}}$ & $\begin{array}{c}\mathrm{A}_{\mathrm{f}} \\
\left({ }^{\circ} \mathrm{D}\right)\end{array}$ \\
\hline kivuguto & 4 & 14 & 0.26 & $4.5-4.6$ & $73 \pm 4$ \\
\hline Lactococcus lactis & 4 & 14 & 0.25 & $4.5-4.6$ & $72 \pm 5$ \\
\hline Leuconostoc pseudomesenteroides & 7 & 20 & 0.17 & $4.5-4.6$ & $70 \pm 4$ \\
\hline
\end{tabular}

$\mathrm{h}=$ hour; $\mathrm{T}_{\mathrm{L}}$ : lag phase; $\mathrm{T}_{\mathrm{f}}$ : fermentation time at $\mathrm{pH}_{\mathrm{f}}=4.5$ (final $\mathrm{pH}$ ), time required for the $\mathrm{pH}$ to reach $4.5 ; \mathrm{V}_{\mathrm{m}}=\mathrm{maximum}$ acidification velocity at $\mathrm{pH}$ in $\mathrm{g}$ of lactic acid per liter per hour; $\mathrm{A}_{\mathrm{f}}=$ titratable acidity in ${ }^{\circ} \mathrm{D}$ at $\mathrm{pH}_{\mathrm{f}}$. 


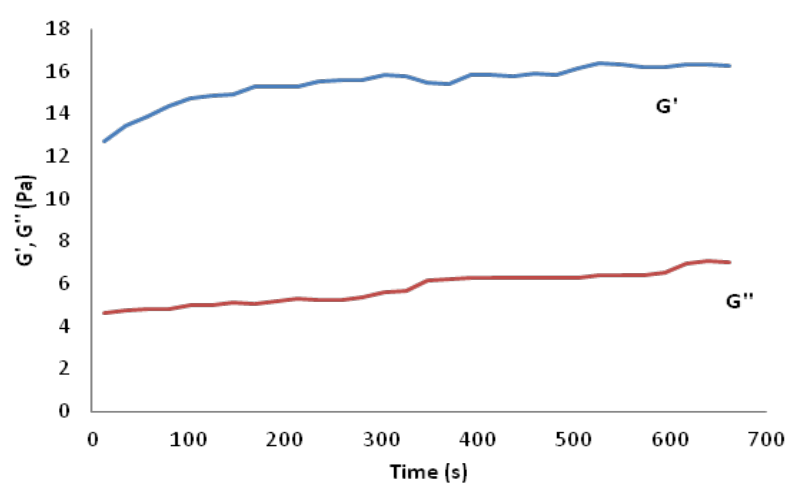

CWBI-B1466 Lactococcus lactis in fermented milk at $\mathrm{pH} 4.5$

Figure 2. Elastic moduli and loss moduli evolution (time in secondes) of the strain

This behavior was also observed for the viscous rigidity of the two types of milk. Storage and loss moduli $\left(\mathrm{G}^{\prime}\right.$ and $G^{\prime \prime}$ respectively) characterize the solid-like (elastic) and liquid-like (viscous) character of fermented milk. However, the ratio of the two parameters, $\tan \delta=\mathrm{G}^{\prime \prime} / \mathrm{G}^{\prime}$, is the best parameter to describe the viscoelastic property of fermented milk.

According to Kristo et al. [22], the higher G' and lower the $\tan \delta$ values, the more solid-like the character of the gel, and the firmer the gel. The data given by the two strains cultured alone show that the milk with the highest value of $\tan \delta$ was the CWBI-B1470 Leuconostoc pseudomesenteroides milk rather than the CWBI-B1466 Lactococcus lactis milk. Second, the experiment assessed the fermentation of a mixture of the two strains with a third non-fermentative strain CWBI-B1465 Leuconostoc mesenteroides subsp. mesenteroides, as the three strains characterize the kivuguto starter. The behavior of the storage moduli and loss moduli in kivuguto was similar to the two types of milk fermented with single strains is that $\mathrm{G}^{\prime}>\mathrm{G}^{\prime \prime}$ and the kivuguto storage moduli $\mathrm{G}^{\prime}<$ to $\mathrm{G}^{\prime}$ of CWBIB1470 Leuconostoc pseudomesenteroides, but $>$ to $\mathrm{G}^{\prime}$ of CWBI-B1466 Lactococcus lactis milk. This is the same for $\mathrm{G}$. The data from these experiments show that the values of $G^{\prime}$ and $G^{\prime \prime}$ of kivuguto were slightly below those of CWBI-B1470 Leuconostoc pseudomesenteroides and characterized kivuguto as a viscoelastic milk.

It is known that the rheological properties of yogurt depend essentially on the ratio of total solids to the milk composition (protein, salts), to milk homogenization, to the type of culture, to acidity $(\mathrm{pH})$, to proteolysis and to the heat treatment undergone by the milk $[23,24]$. This was the same for $G^{\prime \prime}$. Previous studies have shown that lactic acid bacteria produce exopolysaccharides in milk, especially dextrans [15].

Additionally, the incorporation of cultures producing exopolysaccharide into dairy foods can provide viscosifying, stabilizing and water binding functions [25]. The Leuconostocs are good producers of exopolysaccharides (EPS), especially dextrans, which increase the viscosity of milk. The two Leuconostocs composing the kivuguto starter culture are EPS producers, as underlined in previous studies.
Leuconostocs also produce other EPS, like $\alpha$ glucooligosaccharides (GOS) from maltose or isomaltose, which can be used as thickeners or texturizers in cultured milk or as stabilizers $[26,27]$. Glycolysis by the strain of Lactococcus reduced the $\mathrm{pH}$ and consequently the coagulation of milk by modification of the casein structure. Very interestingly, CWBI-B1470 Leuconostoc pseudomesenteroides is involved in three catabolic pathways: acidification by lowering the $\mathrm{pH}$, dextran production by increasing viscosity and aroma generation through citrate metabolism, whilst CWBI-B1465 Leuconostoc mesenteroides subsp. mesenteroides is only a dextran and aroma producer.

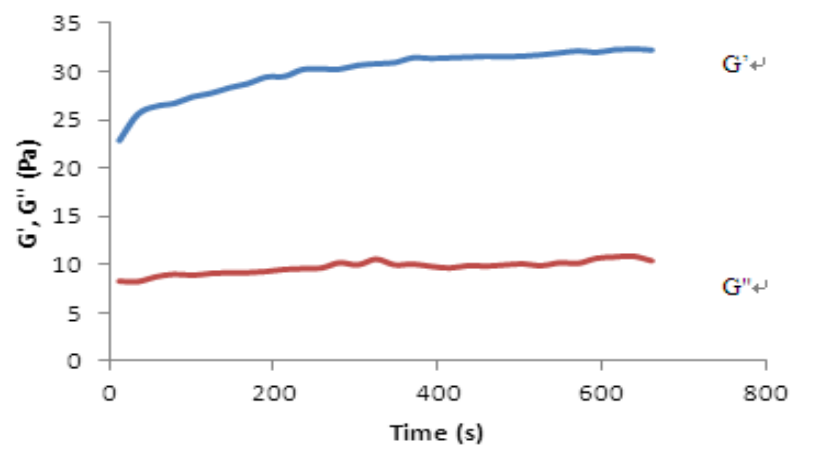

Figure 3. Elastic moduli and loss moduli evolution (time in secondes) of kivuguto fermented milk at $\mathrm{pH} 4.5$

\subsection{Proteolytic Activity}

The proteolysis of milk protein was assessed using the rapid and simple OPA-based spectrophotometric assay [16]. Measurements were performed at inoculation and at the end of fermentation. The data are presented in Table 2 and show the differences for each fermented milk.

A sample of the sterile milk M4 (not inoculated) was also analyzed (results not shown). In this study, the hydrolysis of milk protein by the mixed cultures of kivuguto (Milk M1) released $3.04 \mathrm{mg} / \mathrm{L}$ of peptides/FAAs after the fermentation time, whereas the milk from single fermentation M2 (Lactococcus) and M3 (Leuconostoc) gave 3.11 and 5.45 $\mathrm{mg} / \mathrm{L}$, respectively. The proteolysis analysis revealed greater production in the mixed milk than in the single fermented milks. This may be due to the third strain Leuconostoc mesenteroides which is not fermentative when cultured alone. These data show low concentrations of peptides for all samples, meaning low proteolysis activity. This is very important because high proteolysis values are an indication of bitter peptide production. These values are very similar to those reported by other authors in various fermented products.

Thivierge [28] found an increase in milk proteolysis ranging from 0.33 to $64.58 \mathrm{mg} / \mathrm{L}$ with 26 isolates of Lactococcus spp. More analyses allowed the selection of only strains with proteolysis values of 0.33 to $7.70 \mathrm{mg} / \mathrm{L}$ as presumptive cheese starter cultures. Canas et al. [29] obtained an increase of $6.50 \mathrm{mg} / \mathrm{L}$ in total amino acids during spontaneous malolactic fermentation of wine by 
yeasts and Oenococcus oeni. Production of extracellular peptidases and proteases, which are secreted by some strains of Oenococcus oeni [30], could have contributed to this increase.

Table 2. Proteolysis of milks fermented by kivuguto strains

\begin{tabular}{|c|c|}
\hline Milk & $\begin{array}{c}\text { Concentration of peptides/free amine acids at the } \\
\text { fermentation time Tf }(\mathrm{mg} / \mathrm{L})\end{array}$ \\
\hline M1 & $3.04 \pm 0.73$ \\
\hline M2 & $3.11 \pm 0.30$ \\
\hline M3 & $5.45 \pm 0.16$ \\
\hline M4 & $<0$ \\
\hline
\end{tabular}

M1 mixed culture; M2 Lactococcus culture, M3 Leuconostoc culture and M4 without culture

Streptococcus thermophilus and Lactobacillus delbrueckii subsp. bulgaricus have been reported to express cell-surface proteinases. However, the free amino groups found in milk were very low compared with those of the sample made with the addition of a protease [31]. Prior to performing analyses, Abdel Rahman et al. [32] filtered camel milk samples using Whatman filter paper and found about 60-fold of our results. Moreover, the amount of free amino acids was higher in a mixed starter cultures of Lactobacillus bulgaricus and Streptococcus thermophilus than in the corresponding single cultures. Fortina et al. [33] obtained low proteolytic activities for most strains of Lactococcus garvieae to be used as a dairy starter culture. The mean value was 42.7 g. $\mathrm{L}^{-1}$.

\subsection{Aroma Compound Analysis}

Seven compounds were identified by the comparison of their mass spectra with those described in three libraries, with data from the literature and with Kovats index (KI) of standard compounds run under similar conditions [34]. The results (Table 3 ) are reported together with their relative area and estimated concentrations: 3-methylbutan-1-ol, pentan-1-ol, acetic acid, methyl benzoate, furanmethan-2-ol, 1,7,7-trimethylbicyclo [2.2.1]hept-2yl acetate, and furan2(5)H-one were clearly identified. Other compounds were also detected, but their signal/noise ratios and their very low concentrations prevent unambiguous identification. Two compounds (namely methyl benzoate and 1,7,7trimethylbicyclo [2.2.1] hept-2yl acetate) belong to the UHT milk as they were found in the four samples used for analyses, and are therefore not discussed in this work. The three strains produce aroma compounds: CWBI-B1466 Lactococcus lactis produced pentan-1-ol and 3methylbutan-1-ol; CWBI-B1470 Leuconostoc pseudomesenteroides also produced pentan-1-ol and 3methylbutan-1-ol; CWBI-B1465 Leuconostoc mesenteroides subsp. mesenteroides contributed with the rest of the molecules found in kivuguto, i.e. acetic acid, furanmethan-2-ol, furan-2(5)H-one. This consequently showed a high potential as a flavoring strain which is what it had been selected for; we were sure that it was not a fermentative strain, but might have a huge technological impact on kivuguto milk production. Our results show that kivuguto is characterized by a typical profile of volatile components from various sources like acids, alcohol, lactone, esters, etc., resulting from the various metabolic pathways of the strains of Lactococcus and Leuconostoc. Considering the kivuguto flavor profile, we can suggest that the selected kivuguto strains have their own amino acid convertases, which matches with their ability to produce unusual flavors [35]. The esterification of 3-methylbutan-1ol/pentan-1-ol from acetic acid gives isoamyl acetate/amyl acetate (pentyl acetate), which smell like banana. According to Arctander [36], acetic acid has an acid taste perceptible well below $1 \%$ in water. It has a vinegary, pungent aromatic note with a perception threshold of 22 to $54 \mathrm{ppm}$ in water [37,38] and 3 to $7 \mathrm{ppm}$ in butter [37, 39-41]. Also, lactones are known as a source of pleasant milk flavor. Gadaga et al. [42] evaluated amasi milk and found acetaldehyde, ethanol, acetone, 2-methyl propanal, 2-methylpropan-1-ol, 3-methyl butanal and 3-methylbutan-1-ol as important compounds in the flavor profile of this naturally fermented milk of Zimbabwe. Among these molecules, the most important were ethanol and 3-methylbutan-1-ol. Note that the amasi starter contains nine yeasts and four lactic acid bacteria. Our results are likely in accordance with Ayad et al. [35] who reported that wild strains of Lactococcus lactis are able to produce flavors different from those produced by industrial strains, mostly methyl alcohols and methyl aldehydes. 3-methylbutan-1-ol/pentan-1-ol can be derived from the reduction of the aldehydes formed via Strecker degradation from the amino acids: alanine, valine and leucine [43]. These free amino acids are catabolized by casein proteolysis. Thereafter, acetaldehyde quickly oxidizes into acetic acid in the presence of aldehyde dehydrogenase (Al-DH) via nicotinamide-adenine dinucleotide (NAD) [44]. 3-methylbutan-1-ol/pentan-1-ol can also be derived from lactose fermentation. Alonso \& Fraga [10] used the same method to analyze yogurt flavor compounds and obtained acetaldehyde, acetone, butanone, butan-2,3-dione (diacetyl), 3-hydroxybutanone (acetoin) and acetic acid. These compounds are the result of the catabolism of Lactobacillus delbruecki subsp. bulgaricus and Streptococcus thermophilus as strains used to ferment yogurt. Apart from work on yeasts, there is little information on the production of furanones by microorganisms, although there is a suggestion that some species of Lactobacillus can produce the two forms of furanones [45]. Furanones provide the aroma found in Emmental cheese. According to Slaughter [46], two foodderived furanones have antioxidant activity comparable to that of ascorbic acid. 
Table 3. Headspace analyses of volatile compounds (VCs) in kivuguto milk

\begin{tabular}{|c|c|c|c|c|c|c|c|c|c|c|c|c|}
\hline \multirow[t]{2}{*}{$\mathrm{t}_{\mathrm{r}}^{(1)}$} & \multirow{2}{*}{$\begin{array}{l}\text { CAS }^{(2)} \\
\text { Number }\end{array}$} & \multirow[t]{2}{*}{ IUPAC Name } & \multirow{2}{*}{ Identification $^{(3)}$} & \multicolumn{4}{|c|}{ VCs in milk ${ }^{(4)}$} & \multirow{2}{*}{$\begin{array}{l}\text { Sample } \\
\mathrm{RI}^{(5)}\end{array}$} & \multirow{2}{*}{$\begin{array}{l}\text { Reference } \\
\mathrm{KI}^{(6)}\end{array}$} & \multirow{2}{*}{$\begin{array}{l}\text { Relative area } \\
(\% \pm \mathrm{SD}, \mathrm{n}=3)\end{array}$} & \multirow{2}{*}{$\begin{array}{c}\text { Estimated } \\
\text { concentration }^{(7)} \\
(\mathrm{mg} / \mathrm{kg} \pm \mathrm{SD}, \mathrm{n}=3)\end{array}$} & \multirow{2}{*}{$\begin{array}{l}\text { Observed mass spectrum }^{(8)} \\
\mathrm{m} / \mathrm{z}(\%) \text { for }>10 \%\end{array}$} \\
\hline & & & & M1 & M2 & M3 & M4 & & & & & \\
\hline 8.46 & $123-51-3$ & 3-methylbutan-1-ol & MS, STD, RI & + & + & + & - & 1202 & $1204^{\mathrm{a}}$ & $11.53 \pm 0.64$ & $0.051 \pm 0.003$ & $\begin{array}{c}88(<1) ; 79(15), 69(54) ; 57(29) ; 55(100) ; 55(13) ; \\
45(11) ; 43(51) ; 41(62) ; 41(56) ; 38(25)\end{array}$ \\
\hline 8.92 & 71-41-0 & pentan-1-ol & MS, STD, RI & + & + & + & - & 1226 & $1244^{\mathrm{b}}$ & $18.72 \pm 0.31$ & $0.083 \pm 0.001$ & $\begin{array}{c}70(97) ; 56(29) ; 56(16) ; 55(100) ; 44(11) ; 43(52) ; \\
42(70) ; 40(71) ; 38(31)\end{array}$ \\
\hline 14.26 & $64-19-7$ & acetic acid & MS, STD, RI & + & - & - & - & 1473 & $1477^{\mathrm{c}}$ & $4.37 \pm 0.38$ & $0.154 \pm 0.014$ & 60(67); 45(94); 43(100); 41(19) \\
\hline 16.61 & $93-58-3$ & methyl benzoate & MS, STD, RI & + & + & + & + & 1613 & $1635^{\mathrm{d}}$ & $3.99 \pm 0.005$ & $0.079 \pm 0.001$ & $\begin{array}{c}136(<1) ; 136(33) ; 105(100) ; 77(58) ; 51(21) ; \\
50(10) ; 42(14)\end{array}$ \\
\hline 17.14 & $98-00-0$ & furanmethan-2-ol & MS, STD, RI & + & - & - & - & 1650 & $1661^{\mathrm{e}}$ & $39.9 \pm 1.59$ & $0.177 \pm 0.007$ & $\begin{array}{c}98(46) ; 94(10) ; 81(59) ; 69(30) ; 69(27) ; 54(12) ; \\
53(49) ; 51(18) ; 50(16) ; 42(11) ; 41(52) ; 41(42) ; \\
38(47) ; 38(14)\end{array}$ \\
\hline 17.91 & $92618-89-8$ & $\begin{array}{l}\text { 1,7,7-trimethylbi } \\
\text { cyclo[2.2.1]hept- } \\
\text { 2yl acetate }\end{array}$ & MS, STD, RI & + & + & + & + & 1699 & $1584^{\mathrm{f}}$ & $5.77 \pm 0.005$ & $0.115 \pm 0.001$ & $\begin{array}{l}\text { 196(<1); 137(14); 136(57); 121(52); 110(29); } \\
\text { 109(30); 108(29); 106(12); 95(100); 94(12); } \\
\text { 93(66); 92(20); 91(16); 83(14); 81(17); 79(12); } \\
\text { 78(12); 77(12); 69(22); 67(10); 66(26); 55(14); } \\
\text { 54(86); 53(14); 44(13); 42(13); 40(47); 38(15) }\end{array}$ \\
\hline 18.49 & $497-23-4$ & furan-2(5H)-one & MS, STD, RI & + & - & - & - & 1739 & - & $15.68 \pm 1.03$ & $0.312 \pm 0.020$ & $83(60) ; 54(100) ; 54(21) ; 39(21) ; 36(10)$ \\
\hline
\end{tabular}

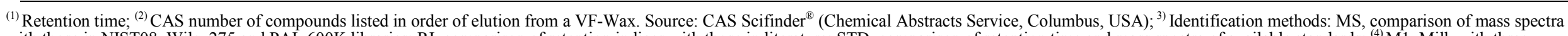

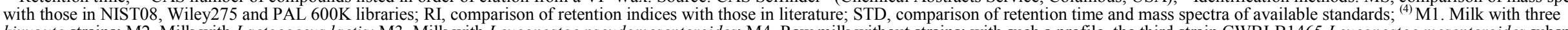

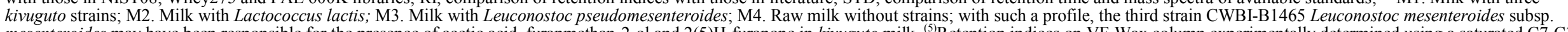

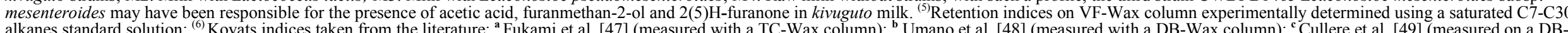

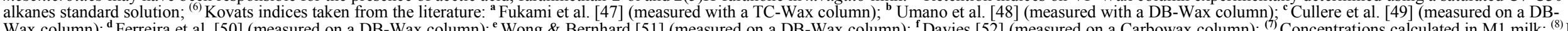

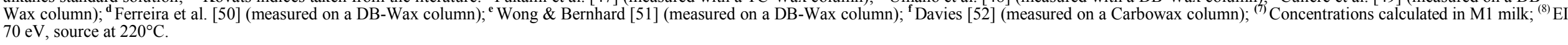




\subsection{Sensory Analysis}

The sensory properties of the samples were evaluated by panelists to find which sample was the closest to kivuguto milk. Samples were the milks made by selected kivuguto strains, yogurt and the commercial fermented milk sold in Rwanda. Panelists were assumed to have consumed the three milks. The first set was composed of a sample of kivuguto with yogurt and the second set of kivuguto and the fermented milk sold in Rwanda. Each set was assayed by the panel and each panelist tasted three cups distributed on a plate. In random order, the panel of eight subjects identified the kivuguto among the other samples with significant differences found for the first set $(\mathrm{P}=0.05)$ and the second set $(\mathrm{P}=0.01)$. The results show that the panel easily detected differences between samples. Moreover, they were able to recognize which sample was made by the kivuguto starter.

\section{Conclusions}

The characterization of kivuguto milk and milks fermented by two strains of kivuguto starter in monoculture was studied regarding four technological properties: acidification, rheology, proteolysis and flavor compounds. The results of this study allowed for the evaluation of the acidification level and counts of bacteria in milk made by selected kivuguto starters, as well as the viscoelastic properties. These properties showed how far the kivuguto rheology can be compared with other fermented milks, like yogurt, filmjölk and leben. Assessment of the static headspace by GC coupled to mass spectrometry is a suitable method for the extraction and analysis of volatile compounds in fermented milks and revealed the kivuguto aroma profile. The discrimination test by a sensory panel also detected differences in kivuguto milk compared to other milks. Our findings show that the selection procedure satisfactorily provided a starter culture for manufacturing kivuguto milk.

\section{Acknowledgements}

The authors wish to express gratitude to Gembloux AgroBio Tech ULG, the CWBI and the CUD for financial support. The authors gratefully appreciate the panelists for their participation in the sensory evaluation. The authors also acknowledge V. Hote, D. Trisman, F. Michels, P. Dzaomuho and S. Filocco for their technical assistance and Proof-Reading-Service (http://www.proof-readingservice.com/guide/index.html) for proof-reading the text.

\section{REFERENCES}

[1] J.A. Kurmann, J.L. Rasic, M. Kroger. Encyclopedia of fermented fresh milk products. Van Nostrand Reinhold, New
York, USA, p368, 1992.

[2] P.L.H. McSweeney, M.J. Sousa. Biochemical pathways for the production of flavor compounds in cheeses during ripening: a review. Lait, vol.80, 293-324, 2000.

[3] A. Zourari, J.P. Accolas, M.J. Desmazeaud. Metabolism and biochemical characteristics of yogurt bacteria. A review. Lait, vol.72, 1-34, 1992.

[4] J. Debon, E.S. Prudêncio, J.C.C. Petrus. Rheological and physico-chemical characterization of prebiotic microfiltered fermented milk. Journal of Food Engineering, vol.99, 128$135,2010$.

[5] H.A. Mohameed, B. Abu-Jdayil, A. Al-Shawabkeh. Effect of solids concentration on the rheology of labneh (concentrated yogurt) produced from sheep milk. Journal of Food Engineering, vol.61, 347-352, 2004.

[6] H. Chibane. Aptitudes technologiques de quelques variétés de dattes: formulation d'un yaourt naturellement sucré et aromatisé. Thèse. Université M'Hamed BougaraBoumerdes, Algérie, p203, 2008.

[7] M. Maskan, F. Gogus. Effect of sugar on the rheological properties of sunflower oil-water emulsion. Journal of Food Engineering, vol.43, 173-177, 2000.

[8] J.F. Steffe. Rheological Methods in Food Process Engineering. $2^{\text {nd }}$ ed. Freeman Press, East Lansing, p412, 1996.

[9] S.D. Holdsworth. Rheological models used for the prediction of flow properties of food products. Transactions in Chemical Engineering, vol.71, 139-179, 1993.

[10] L. Alonso, M.J. Fraga. Simple and rapid analysis for quantification of the most important volatile flavor compounds in yogurt by headspace gas chromatographymass spectrometry. Journal of Chromatographic Science, vol.39, 2001.

[11] E.L. Thomas. Trends in milk flavors. Journal of Dairy Science, vol.64, 1023-1027, 1981.

[12] H.E. Nursten. The flavour of milk and dairy products: I. Milk of different kinds, milk powder, butter and cream. International Journal of Dairy Technology, vol.50, 2, 1997.

[13] A.Y. Tamime, H.C. Deeth. Yogurt: technology and biochemistry. Journal of Food Protection, vol.43, 939-977, 1980.

[14] E. Karenzi, R.D. Dauphin, A. Mashaku, L. Majad, B. Munyanganizi, P. Thonart. Fermentation of kivuguto, a Rwandese traditional milk: Selection of microbes for a Starter Culture. Sciences \& Technologie C., vol.36, 9-17, 2012.

[15] P. Stern, J. Pokorny, A. Sediva, Z. Panovska. Rheological and sensory characteristics of yogurt-modified mayonnaise. Czech Journal of Food Science, vol.26, 190-198, 2008.

[16] F.C. Church, H.E. Swaisgood, D.H. Portier, G.L. Catignani. Spectrophotometric assay using o-phthaldialdehyde for determination of proteolysis in milk and isolated milk proteins. Journal of Dairy Science, vol.66, 1219-1227, 1983.

[17] E. Kovats. Gaz-chromatographische charakterisierung organishcher verbindungen. Teil 1: Retentions indices aliphatischer Halogenide, Alkohole, Aldehyde und Ketone. Helvetica Chimica Acta, vol.41, 1915-1932, 1958. 
[18] D.C. Harris. Quantitative chemical analysis, W.H. Freeman and Company, New York, USA, p818, 1987.

[19] S. Delacharlerie, S. de Biourge, C. Chèné, M. Sindic, C. Deroanne. HACCP organoleptique: Guide pratique. Presses agronomiques de Gembloux, Belgique, p176, 2008.

[20] V. Juillard, H.E. Spinnler, M.J. Desmazeaud, C.Y. Boquien. Phénomène de coopération et d'inhibition entre les bactéries lactiques utilisées en industrie laitière. Lait, vol. 67, 149-172, 1987.

[21] M.N. Oliveira, F. Remeuf, G. Corrieu. Effect of milk supplementation and culture composition on acidification, textural properties and microbiological stability of fermented milks containing probiotic bacteria. International Dairy Journal, vol.11, 935-942, 2001.

[22] E. Kristo, C.G. Biliaderis, N. Tzanetakis. Modelling of rheological, microbiological and acidification properties of a fermented milk product containing a probiotic strain of Lactobacillus paracasei. International Dairy Journal, vol.13, 517-528, 2003.

[23] C.G. Biliaderis, M.M. Khan, G. Blank. Rheological and sensory properties of yoghurt from skim milkband ultrafiltred retentates. International Dairy Journal, vol.2, 311-323, 1992

[24] I. Heertje, J. Visser, P. Smits. Structure formation in acid milk gels. Food Microstructure, vol.4, 267-277, 1985.

[25] J.R. Broadbent, D.J. Mahon, C.J. Oberg, S. Moineau. Biochemistry genetics and applications of exopolysaccharides production in Streptococcus thermophilus. Journal of Dairy Science, vol.86, N², 407423, 2003.

[26] J.I. Sanchez, B. Martinez, A. Rodriguez. Rationale selection of Leuconostoc strains for mixed starters based on the physiological biodiversity found in raw milk fermentations. International Journal of Food Microbiology, vol.105, 377387, 2005.

[27] E.R. Vedamuthu. The dairy Leuconostoc: use in dairy products. Journal of Dairy Science, vol.77, 2725-2737, 1994.

[28] N. Thivierge. Caractérisation de souches de Lactococcus lactis subsp. cremoris pour le développement de ferments mésophiles à aptitudes fromagères élevées (Cheddar). Université Laval, Canada, p74, 1999.

[29] P.M. Canas, E.G. Romero, S. Gomez-Alonso, M.F Gonzalez, M.L.P. Herreros. Amino acids and biogenic amines during spontaneous malolactic fermentation, 2007. Online available: http://www.oiv2007.hu/ documents/viniculture/107_amino acids and biogeni c_amines_during_spontaneous_malolactic_fermentati on.pdf. Accessed on September 15, 2013.

[30] F. Remize, Y. Augagneur, M. Guilloux-Benatier, J. Guzzo Effect of nitrogen limitation and nature of the feed upon Oenococcus oeni metabolism and extracellular protein production. Journal of Applied Microbiology, vol.98, 652$661,2005$.

[31] W. Phiromruk, A. Jarerat, P. Luangpituksa, T. Amatayakul. Production of fermented milk high in activity of angiotensin converting enzyme inhibition by extending fermentation time and protease addition. Asian Journal of Food and AgroIndustry, vol.2, $\mathrm{N}^{\circ} 4,167-174,2009$.

[32] I.E. Abdel Rahman, H.A. Dirar, M.A. Osman.
Microbiological and biochemical changes and sensory evaluation of camel milk fermented by selected bacterial starter cultures. African Journal of Food Science, vol.3, $\mathrm{N}^{\circ} 12,398-405,2009$.

[33] M.G. Fortina, G. Ricci, R. Foschino, C. Picozzi, P. Dolci, G. Zeppa, L. Cocolin, P.L. Manachini. Phenotypic typing, technological properties and safety aspects of Lactococcus garvieae strains from dairy environments. Journal of Applied Microbiology, vol.103, 445-453, 2007.

[34] R.P. Adams. Identification of essential oil components by gas chromatography/mass spectroscopy. Allured Publishing Corporation, 1-69. Illinois, USA, 1995.

[35] E.H.E. Ayad, A. Verheul, C. De Jong, J.T.M. Wouters, G. Smit. Flavour forming abilities and amino acid requirements of Lactococcus lactis strains isolated from artisanal and nondairy origin. International Dairy Journal, vol.9, 725-735, 1999.

[36] S. Arctander. Perfume and flavor chemicals (Aroma chemicals) I. Rutgers University. Allured Publishing Corporation. Montclair, New Jersey, USA, 1969.

[37] P. Molimard, H. Spinnler. Compounds involved in the flavor of surface mold-ripened cheese: origins and properties. Journal of Dairy Science, vol.79, 169-184, 1996.

[38] H. Boelens, H.G. Harding, D. De Rijke. Threshold values of and human preference for 4-ethyloctanoic and 3methylbutanoic acid. Perfumer and Flavorist, vol.8, 71-74, 1983.

[39] G. Urbach, W. Stark, D.A. Forss. Volatile compounds in butter oil. II. Flavour and flavour thresholds of lactones, fatty acids, phenols, indole and skatole in deodorized synthetic butter. Journal of Dairy Research, 39, 35-47, 1972.

[40] T.J. Siek, I.A. Albin, L.A. Sathe, R.C. Lindsay. Taste thresholds of butter volatiles in deodorized butteroil medium. Journal of Food Science, vol.34, 265-267, 1969.

[41] S. Patton. Flavor threshold of volatile fatty acids. Journal of Food Science, vol.29, 679-680, 1964.

[42] T.H. Gadaga, B.C. Viljoen, J.A. Narvhus. Volatile organic compounds in fermented milk. Food Technology and Biotechnoly, vol.45, N², 195-200, 2007.

[43] J.M. Izco, P. Torre. Characterization of volatile avour compounds in Roncal cheese extracted by the purge and trap method and analyzed by GC-MS. Food Chemistry, vol.70, 409-417, 2000.

[44] M. Hruskar, N. Major et al. Simultaneous determination of fermented milk aroma compounds by a potentiometric sensor array. Talanta, vol.82, N4, 1292-1297, 2010.

[45] N.B. Carter, A.E. Nadany, J.B. Sweeney. Recent developments in the synthesis of furan-2 $(5 \mathrm{H})$-one. Journal of Chemistry Society, Perkin Trans. vol.1, 2324-2342, 2000.

[46] J.C. Slaughter. The naturally occurring furanones: formation and function from pheromone to food. Biological Reviews, vol.74, N³, 259-276, 1999.

[47] K.Fukami, S. Ishiyama, H. Yaguramaki, T. Masuzawa, Y. Nabeta, K. Endo, M. Shimoda. Identification of distinctive volatile compounds in fish sauce. Journal of Agricultural and Food Chemistry, vol.50, $\mathrm{N}^{\circ} 19,5412-5416,2002$.

[48] R.P. Umano, Y. Hagi, T. Shibamoto. Volatile chemicals 
identified in extracts from newly hybrid citrus, Dekopon (Shiranuhi mandarin Suppl. J.). Journal of Agriculture and Food Chemistry, vol.50, 5355-5359, 2002.

[49] L. Culleré, A. Escudero, J. Cacho, V. Ferreira. Gas chromatography-olfactory and chemical qualitative study of the aroma of six premium quality Spanish aged red wines. Journal of Agriculture and Food Chemistry, vol.52, 16531660, 2004.

[50] V. Ferreira, M. Aznar, R. Lopez, J. Cacho. Quantitative gas chromatography-olfactometry carried out at different dilutions of an extract. Key differences in the odor profiles of four high-quality Spanish aged red wines. Journal of Agriculture and Food Chemistry, vol.49, 4818-4824, 2001.

[51] J.M. Wong, R.A. Bernhard. Effect of Nitrogen source on pyrazine formation. Journal of Agricultural and Food Chemistry, vol.36, 123-129, 1988.

[52] N.W. Davies. Gas chromatographic retention indices of monoterpenes and sesquiterpenes on methyl silicone and carbowax 20M phases. Journal of Chromatography A, 503, 1-24, 1990. 